\title{
Finding the funding for agriculture
}

Sir - I appreciate the timely appearance of the article and editorial on the support of US agricultural science (Nature 394, 207 \& 210-211; 1998). They should serve to inform the scientific public about how science at the US Department of Agriculture (USDA) is currently funded and the uncertain future of the authorized new monies that would provide additional funding for plant and animal genome research (among other topics). The article also stressed the beleaguered state of the National Research Initiative (NRI), the department's competitive grants arm, where I am chief scientist on leave from the University of Missouri.

I want to emphasize that the NRI does more than support plant science. There are 29 panels, covering all aspects of agricultural research, from economics to genomics. Yes, the plant people have a tough time compared with the typical investigator funded through the US National Institutes of Health (NIH), but, with ingenuity, they can get support from the National Science Foundation or even the Department of Energy. There is still some plant science funded by the NIH, if the work is properly dressed up to be health related.

There are, however, certain areas where the NRI is about the only source of federal funds. Consider, for example, the individual working on an agricultural project to study the interaction between grazing, plants, soils and water, or university scientists studying animal diseases that are not 'models' useful in human medicine. There are also broad areas of animal science that are understandably unpalatable to NIH; ruminant nutrition or lactation don't exactly appeal to study sections, and who is going to fund competitive grants for genomics of agriculturally important animal species, if not the NRI?

I am on temporary $(60 \%)$ assignment to the USDA. I can afford to do this only because of the indulgence of my university and because I am well funded by NIH on projects that, in a more logical setting, would be of at least equal interest to agriculture as to human health.

A sorry footnote is that the NRI may lose a further $\$ 5$ million of its already small appropriation because of an amendment to pay for a fiscal obligation elsewhere in the USDA unrelated to competitive grants.

\section{R. Michael Roberts}

158 Animal Sciences Research Center, University of Missouri, Columbia,

Missouri 65211, USA

e-mail: robertsrm@missouri.edu

\section{1 uses for a natural}

\section{history museum}

Sir - The Briefing about natural history museums was very informative but the editorial, "101 uses for a dead bird", promotes a number of misconceptions (Nature 394, 105 \& 115-119; 1998).

Museum collections are, as you recognize, the ultimate basis of most if not all biodiversity studies, including those that permit the decline in biodiversity to be monitored and controlled. Principal input is through the discipline of systematics, that is, the recognition of species, their variation and their relationships. Systematics condenses the vast amounts of disparate information in large numbers of specimens from many localities and puts it in comprehensible and usable form. Museums also act as repositories for other data including those on species distribution.

Systematics and related data collection have been pursued with increasing pace in natural history museums since their foundation, often in the nineteenth or even eighteenth centuries. Strong internal cultures within museums have helped ensure continued systematic output, even in conditions of considerable adversity. Any implication that museums and similar institutions have not previously been conducting what are essentially biodiversity studies is wrong; they are the very places where such investigations have been predominantly carried out.

You also state that museums have been parochial and "can no longer afford to work in isolation". In the vast majority of cases, they never were and never did. There has been extensive global cooperation between large museums for nearly 200 years. For example, George Boulenger, the lone curator of lower vertebrates at the Natural History Museum in London, exchanged information in ten years around the turn of the century with some 700 correspondents, many in museums in other countries, including 20 in Italy alone. Such large-scale interaction is far more extensive today. Not only information but study specimens constantly pass between museums around the world and have done so for many years. In the Natural History Museum, many hundreds of loans involving tens of thousands of specimens are dispatched annually.

There is already a great deal of cooperation between relatively rich and poor nations, including the case you mention of Mexico's National Commission of Knowledge and Use of Biodiversity, which sent scientists to museums worldwide to assemble data on Mexican specimens. The commission is to be congratulated on producing cheaply a biodiversity management system by making use of these data, but it must be remembered that the information was readily available because museums cooperated willingly and actively in the project. More importantly, they had previously put a far greater amount of effort and expense into accumulating and curating the material, painstakingly identifying it and subjecting it to further systematic analysis, resulting in the description of many new species, and making the data easily accessible. After all this, putting the information into a database as the Mexicans did was comparatively easy.

\section{Nicholas Arnold}

Department of Zoology, Natural History Museum, Cromwell Road, London SW7 5BD, UK

\section{German ambivalence to genetic engineering}

Sir - You reported the results of a German project on perceptions of biotechnology, saying that Germans are deeply suspicious of genetic engineering and that expectations are predominantly negative (Nature 393, 299; 1998). But our study shows that the predominant attitude of Germans towards genetic engineering is in fact ambivalence.

Half the population thinks that genetic engineering is neither good nor bad. Along with this ambivalent perception of genetic engineering in general, there are rather clear, and differentiated, reactions to specific applications of genetic engineering. Fewer than $2 \%$ of the sample either agree with or reject all applications.

Medical and pharmaceutical applications are accepted at the same level as other positively evaluated, uncontested technologies, for example computer and information technologies. Agricultural applications are still not accepted. Jürgen Hampel Center of Technology Assessment in BadenWürttemberg, Industriestrasse 5, D-70565 Stuttgart, Germany 